\title{
Advanced nanocarriers for an antitumor peptide
}

Natassa Pippa ${ }^{1,2}$, Stergios Pispas $^{2}$, Costas Demetzos $^{1, *}$, Gregory Sivolapenko ${ }^{3}$

${ }^{1}$ Department of Pharmaceutical Technology, Faculty of Pharmacy, National and Kapodistrian University of Athens, Athens, Greece

${ }^{2}$ Theoretical and Physical Chemistry Institute, National Hellenic Research Foundation, Athens, Greece

${ }^{3}$ Laboratory of Pharmacokinetics, Department of Pharmacy, University of Patras, Patra, Greece

${ }^{(*)}$ Corresponding author: Prof. Costas Demetzos, Faculty of Pharmacy, Department of Pharmaceutical Technology, Panestimiopolis Zografou 15771, University of Athens, Athens, Greece; fax: 00302107274027; e-mail: demetzos@pharm.uoa.gr 


\begin{abstract}
In this work, tigapotide (PCK3145) was incorporated into novel nanocarriers based on polymeric, lipidic and dendrimeric components, in order to maximize the advantages of the drug delivery process and possibly its biological properties. PCK3145 was incorporated into lipidic nanocarriers composed of Eggphosphatidylcholine (EggPC) and dipalmytoylphosphatidylcholine (DPPC) (EggPC:PCK3145 and DPPC:PCK3145, 9:0.2 molar ratio), into cationic liposomes composed of EggPC:SA:PCK3145 and DPPC:SA:PCK3145 (9:1:0.2 molar ratio) into complexes with the block polyelectrolyte (quaternized poly[3,5bis(dimethylaminomethylene)hydroxystyrene]-b-poly(ethylene oxide) (QNPHOSEO) and finally into dendrimeric structures (i.e. PAMAM G4) . Light scattering techniques are used in order to examine the size, the size distribution and the z-potential of the nanocarriers in aqueous and biological media. Fluorescence spectroscopy was utilized in an attempt to extract information on the internal nanostructure and microenvironment of polyelectrolyte/PCK3145 aggregates. Therefore, these studies could be a rational roadmap for producing various effective nanocarriers in order to ameliorate the pharmacokinetic behavior and safety issues of antitumor and anticancer biomolecules.
\end{abstract}

Keywords: liposomes; dendrimers; block polyelectrolyte; tigapotide 


\section{Introduction}

Drug delivery has matured from its original goal of prolonging the duration of drug release; it now involves customized systems that are designed to achieve specific spatial and temporal control; future generations of drug-delivery systems will incorporate "smart" biosensing functionalities that will enable unaided in vivo feedback control (Kaditi et al., 2012; Crommelin and Florence, 2013). The properties of an ideal drug delivery or biomedical vector are the structural control over size and shape of drug or imaging-agent cargo-space, biocompatibility, nontoxic polymer/pendant functionality, the lack of immunogenicity and the precise, nanoscale-container and/or scaffolding properties with high drug or imaging-agent capacity features (Rowland et al., 2012; Crommelin and Florence, 2013). From a pharmacokinetic point of view, ideal drug delivery systems have a well-defined scaffolding and/or surface modifiable functionality for cell specific targeting moieties (Crommelin and Florence, 2013).

Liposomes are widely used for entrapment of therapeutic agents, and were developed to increase antitumor efficacy of a wide variety of drug molecule and biomaterials such as peptides and oligonucleotides (Bangham et al., 1965; Gregoriadis et al., 1974; Hofheinz et al., 2005; Slingerland et al., 2012). In two past decades, cationic liposomes have been used extensively for gene delivery (Ruozi et al., 2003). The positive charge on the liposomal surface plays a crucial role because it allows the establishment of strong electrostatic interactions between the liposomal bilayer and the negatively bioactive compounds (Wu and McMillan, 2009; Kapoor et al., 2012). Additionally, the interactions of cationic liposomes with cell membrane models and plasma proteins have been already studied (Bonicelli et al., 2011; Capriotti et al., 2012; Pippa et al., 2012a). 
Furthermore, asymmetric amphiphilic block copolymers self-assemble in aqueous media, to form a core-shell micellar structures and morphologies, with a mesoscopic or nanoscopic narrow size range and are used for biomedical and pharmaceutical applications (in the order of 10-100 nanometers) (Torchilin, 2004, 2009). Polyelectrolyte block copolymers constitute an intriguing class of bio-inspired macromolecules, as they combine the structural properties of amphiphilic block copolymers, polyelectrolytes and surfactants and provide various possibilities for use as delivery nanosystems of genes and proteins through electrostatic complexation (AlTahami and Singh, 2007; Hartig et al., 2007; Pispas, 2007; Reis et al., 2008; Karayianni et al., 2011; Karayianni and Pispas, 2012; Becker et al., 2012; Haladjova et al., 2012; Varkouhi et al., 2012).

Additionally, dendrimers are characterized as the $4^{\text {th }}$ architectural class of polymers and represent a new category of drug delivery nanosystems. Due to their precise architecture, dendrimers possess an advantage over other generally polydisperse nanoparticles and this allows for greater control over their pharmacodynamic profile, while as vehicles for drug delivery they can be used either for encapsulation of bioactive compounds or for their covalent or non-covalent attachment at the periphery (Esfand and Tomalia, 2001; DeMattei et al., 2004; Demetzos, 2006; Chauhan et al., 2009; Tomalia et al., 2007, 2009; Menjoge et al., 2010). Cheng et al. (2008) pointed out that dendrimers have successfully proved themselves as useful additives in different routes of drug administration (intravenous, oral, transdermal, and ocular delivery systems) because they can render greater water-solubility and bioavailability to drugs. An ideal dendrimer, which is a highly branched macromolecule, must be non-toxic, non-immunogenic and biodegradable in order to be considered as a nanostructured drug delivery system (Cloninger, 2002; Aulenta et al., 2003). The first 
complete dendrimer family which has been synthesized, characterized and commercialized is the Poly(amidoamine) (PAMAM) dendrimers. They are characterized as safe and non-immunogenic and they are used in drug delivery, delivery of antisense nucleotides and gene therapy, both in vitro and in vivo due to the reproducibility of their pharmacokinetic behavior (Eichman et al., 2001; Asthana et al., 2005; Svenson and Tomalia, 2005). According to the literature, dendrimers have been shown to cross cell barriers and membranes by the mechanism of endocytosis (Jevprasesphant et al., 2004; Sadekar and Ghandehari, 2012).

Modulatory Controlled Release profile (MCR) denoted as Modulatory Controlled Release nano Systems (MCRnSs) are considered as drug delivery systems that can modulate the release of the encapsulated bioactive compound (Gardikis et al., 2010, 2011; Pippa et al., 2013a,b,c,d). The nature of the elements used for producing advanced biomaterials are of great importance and medicinal chemistry and new synthetic bioelements (i.e. new polymeric and dendritic structures) play a crucial role in their production (Tomalia, 2009).

It has been reported that a synthetic 15-mer peptide, tigapotide (PCK3145), derived from prostate secretory protein, can reduce tumor growth, experimental skeletal metastases, and melignacy associated hypocalcaemia (Shukeir et al., 2004; Annabi et al., 2005, 2006). Additionally, it has being shown that the incorporation of bioactive compounds with antitumor effects into nanocarriers modified their cellular uptake by favoring the selective accumulation in cell membranes from where they had demonstrated prolonged release (Crommelin and Florence, 2013).

The goal of this study is to design and develop effective nanocarriers for tigapotide based on polymeric, lipidic and dendritic components. Prime interest is focused on the 
determination of the physicochemical (i.e. size, $\zeta$-potential, Polydispersity Index (PD.I.), and morphology) of the produced nanoparticles. We employ dynamic (DLS), static (SLS) and electrophoretic (ELS) light scattering in order to examine the complexation process, as well the structure and solution behavior of the nanosized complexes in aqueous and biological media, formed between quaternized poly[3,5bis(dimethylaminomethylene)hydroxystyrene]-b-poly(ethylene oxide) (QNPHOSEO), a cationic-neutral block copolymer, and PCK3145. The physicochemical characteristics and stability studies of different liposomal formulations (DPPC:PCK3145 and EggPC:PCK3145 (9:0.2 molar ratio) and DPPC:SA:PCK3145 and EggPC:SA: PCK3145 (9:1:0.2 molar ratio) incorporating tigapotide are also presented in this work. The purpose of this study also includes the examination of the complexation process of PAMAM-G4 dendrimer with PCK3145.

\section{Experimental}

\section{Materials}

The phospholipids used for liposomal formulations were Egg phosphatidylcholine (EggPC) and 1,2-dipalmitoyl-sn-glycero-3-phosphocholine (DPPC). They were purchased from Avanti Polar Lipids Inc., (Albaster, AL, USA) and used without further purification. Chloroform, Stearylamine (SA, Octadecylamine) and all other reagents used were of analytical grade and purchased from Sigma-Aldrich Chemical Co. PAMAM Dendrimer generation 4 (empirical formula $\mathrm{C}_{622} \mathrm{H}_{1248} \mathrm{~N}_{250} \mathrm{O}_{124}$, formula weight: 14214.17) was purchased from Aldrich. The synthesis, the physicochemical characterization, as well as the properties of QNPHOSEO are presented extensively in the recent literature (Mountrichas et al., 2006; Mountrichas and Pispas, 2007; Mantzaridis et al., 2009; Stepanek et al., 2011). The QNPHOSEO polyelectrolyte block copolymer was characterized by SEC, ${ }^{1} \mathrm{H}-\mathrm{NMR}$ and FTIR and it was found to 
have the following molecular characteristics: $\mathrm{M}_{\mathrm{w}}=98,600, \mathrm{M}_{\mathrm{w}} / \mathrm{M}_{\mathrm{n}}=1.09,15 \%$ wt PEO. The Tigapotide (PCK3145) is manufactured at PolyPeptide Laboratories (formerly Neo MPS) via solid phase synthesis incorporating Fmoc (9Fluorenylmethyloxycarbonyl) protective groups. An acetylaminomethyl group is attached to the sulphur at each of the three cysteines within the peptide. The peptide is synthesized as the trifluoroacetate (TFA) salt. The amino acid sequence is as follows: H2N-Glu-Trp-Gln-Thr-Asp-Asn-Cys (AcM)-Glu-Thr- Cys (AcM)-Thr-Cys (AcM)Tyr-Glu-Thr-OH and the chemical formula is $\mathrm{C}_{82} \mathrm{H}_{121} \mathrm{~N}_{21} \mathrm{O}_{34} \mathrm{~S}_{3}$ (molecular weight: 2039.14). The structures of QNPHOSEO, PAMAM G-4 and PCK3145 are presented in Fig. 1. The lipids' chemical structures as well as the structure of dendrimer are is widely known.

Preparation of QNPHOSEO:PCK3145 polyelectrolyte aggregates in different aqueous media

A pH 7 buffer solution was prepared from $\mathrm{NaOH}$ and $5 \mathrm{mM}$ sodium phosphate, Moreover, $10 \mathrm{mM} \mathrm{NaCl}$ were added to solution to maintain a fixed ionic strength, along with $\mathrm{NaN}_{3}$ in a final concentration of 200ppm, in order to avoid bacterial growth. Stock solutions of PCK3145 and of QNPHOSEO were prepared by dissolving a weight amount of the dialyzed sample in the appropriate volume of the buffer and the solutions were left to stand overnight for better equilibration.

The complexes were prepared by adding different amounts of the PCK3145 solutions to QNPHOSEO solutions of the same volume and concentration, under stirring. Finally, appropriate volumes of buffer solutions were added to achieve a constant final volume and ionic strength (equal to that of the buffer solutions) for all solutions prepared. Thus, the concentration of QNPHOSEO was kept constant throughout the series of solutions, while that of PCK3145 varied in order to control the required ratio 
of the two components (or equivalently the $[-] /[+]$ charge ratio of the mixture). The solutions of the complexes developed a bluish tint or turbidity upon mixing, indicating the formation of supramolecular complexes. Subsequently, the solutions of the complexes were left for equilibration overnight, which in some cases resulted in coacervation, i.e. liquid-liquid phase separation of the solution, depending on the PCK3145 concentration and $\mathrm{pH}$. Stable solutions were further characterized as discussed below.

For the ionic strength dependent light scattering measurements, the ionic strength of the solution was gradually increased by the addition of appropriate aliquots of $1 \mathrm{~N}$ $\mathrm{NaCl}$ solution at $\mathrm{pH}=7.00$ or 7.40 , to $1 \mathrm{ml}$ of the previously prepared solutions of the complexes. After each addition the solution was rigorously stirred and left to equilibrate for $15 \mathrm{~min}$ before measurement. Changes in solute concentrations due to $\mathrm{NaCl}$ solution addition were taken into consideration in the analysis of the light scattering data.

Preparation of liposomal nanocarriers

Different liposomal formulations have been prepared using the thin-film hydration method. Briefly, appropriate amounts of DPPC or EggPC and/or EggPC:SA or DPPC:SA mixtures were dissolved in chloroform/methanol $(9: 1 \mathrm{v} / \mathrm{v})$ and then transferred into a round flask connected to a rotary evaporator (Rotavapor R-114, Buchi, Switzerland). Vacuum was applied and the phospholipids thin film was formed by slow removal of the solvent at $50^{\circ} \mathrm{C}$. The mixed film was maintained under vacuum for at least $24 \mathrm{~h}$ in a desiccator in order to remove traces of solvent and subsequently it was hydrated in solution of PCK3145 in Phosphate Buffer Saline (PBS), by slowly stirring for $1 \mathrm{~h}$ in a water bath above the phase transition temperature of lipids $\left(41^{\circ} \mathrm{C}\right.$ for DPPC and $23^{\circ} \mathrm{C}$ for EggPC). The resultant nanostructures 
(apparently multilamellar vesicles, MLVs) were subjected to two, $3 \mathrm{~min}$ and $2 \mathrm{~min}$ sonication cycles (amplitude 70, cycle 0.7 ) interrupted by a 3 min resting period, in a water bath, using a probe sonicator (UP 200S, dr. Hielsher GmbH, Berlin, Germany). The resultant liposomes (tentatively assigned as small unilamellar vesicles, SUVs) were allowed to anneal for 30min. The effect of PCK3145 incorporation in liposomal preparations was evaluated by measuring the size distribution and $\zeta$-potential of the nanocarriers. The mean hydrodynamic diameter was used for the characterization of the liposomal dispersion immediately after preparation ( $t=0$ day), as well as for the monitoring of their physical stability over time.

Preparation of dendritic nanocarriers

The complexes were prepared by adding different amounts of the PCK3145 solutions to PAMAM-G4 solutions and by adding different amounts of the PAMAM-G4 solutions to PCK3145 solutions in different molar ratios, under stirring. Finally, appropriate volumes of buffer solutions were added to achieve a constant final volume and ionic strength (equal to that of the PBS) for all solutions prepared.

\section{Techniques}

Dynamic and static light scattering

The hydrodynamic radius $\left(\mathrm{R}_{\mathrm{h}}\right)$ of nanocarriers and the polydispersity index (PD.I.) were measured by dynamic light scattering (DLS) and the ratio of radius of gyration to hydrodynamic radius $\left(\mathrm{R}_{\mathrm{g}} / \mathrm{R}_{\mathrm{h}}\right)$ was determined by static light scattering (SLS). Mean values and standard deviations were calculated from three independent samples. For dynamic and static light scattering measurements, an AVL/CGS-3 Compact Goniometer System (ALV GmbH, Germany) was used, equipped with a cylindrical JDS Uniphase $22 \mathrm{mV}$ He-Ne laser, operating at $632.8 \mathrm{~nm}$, and an Avalanche photodiode detector. The system was interfaced with an ALV/LSE-5003 electronics 
unit, for stepper motor drive and limit switch control, and an ALV-5000/EPP multitau digital correlator. Autocorrelation functions were analyzed by the cumulants method and the CONTIN software. Apparent hydrodynamic radii, $\mathrm{R}_{\mathrm{h}}$, at finite concentrations, were calculated by aid of the Stokes - Einstein equation:

$R_{h}=\frac{k_{B} T}{6 \pi n_{0} D}$

where $\mathrm{k}_{\mathrm{B}}$ is the Boltzmann constant, $\eta_{0}$ is the viscosity of water at temperature $\mathrm{T}$, and $\mathrm{D}$ is the diffusion coefficient at a fixed concentration. The polydispersity of the particle sizes was given as the ${ }^{\mu_{2}} /_{\Gamma^{2}}$ (PD.I.) from the cumulants method, where $\Gamma$ is the average relaxation rate, and $\mu_{2}$ is its second moment.

Light scattering has been used widely in the study of the fractal dimensions of aggregates. In static light scattering, a beam of light is directed into a sample and the scattered intensity is measured as a function of the magnitude of the scattering vector q, with:

$$
q=\frac{4 \pi n_{0}}{\lambda_{0}} \sin \mathbb{\llbracket}\left(\frac{\theta}{2}\right)
$$

where $\mathrm{n}_{0}$ is the refractive index of the dispersion medium, $\theta$ is the scattering angle and $\lambda_{0}$ is the wavelength of the incident light. Measurements were made at the angular range of $30^{\circ}$ to $150^{\circ}$ (i.e. the range of the wave vector was $0.01<\mathrm{q}<0.03 \mathrm{~cm}^{-1}$ ).

The general relation for the angular dependence of the scattered intensity, I(q) is:

$$
I(q) \sim q^{-d f}(3)
$$


where $d_{f}$ is the fractal dimension of the liposomes or aggregates with $1 \leq d_{f} \leq 3 \quad\left(d_{f}=3\right.$ corresponds to the limit of a completely compact Euclidean sphere where less compact structures are characterized by lower $d_{f}$ values). The above equation is the classical result used to determine the mass fractal dimension from the negative slope of the linear region of a log-log plot of I vs. q.

Electrophoretic mobility - microelectrophoresis

The zeta potential ( $\zeta$-potential) plays an important role in colloidal stability of nanoparticles and can be readily measured by the technique of microelectrophoresis (Delgado et al., 2007). The zeta potential of chimeric nanostructures was measured using Zetasizer 3000HAS, Malvern Instruments, Malvern, UK. $50 \mu \mathrm{l}$ of the dispersions was 30-fold diluted in dispersion medium and $\zeta$-potential was measured at room temperature at $633 \mathrm{~nm}$. The zeta potentials were calculated from electrophoretic mobilities, $\mu_{\mathrm{E}}$, by using the Henry correction of the Smoluchowski equation:

$$
\zeta=\frac{3 \mu_{E} n}{2 \varepsilon_{0} \varepsilon_{r}} \frac{1}{f(\kappa a)}
$$

where $\varepsilon_{0}$ is the permittivity of the vacuum, $\varepsilon_{r}$ is the relative permittivity, $\alpha$ is the particle radius, $\kappa$ is the Debye length, and $n$ is the viscosity of water. The function $f(\kappa \alpha)$ depends on particle shape. While if $\kappa \alpha>1$ :

$$
f(\kappa \alpha)=1.5+\frac{9}{2(\kappa \alpha)}+\frac{75}{2(\kappa \alpha)^{2}}
$$

The above function refers to dispersions of the present study.

Fluorescence Spectroscopy 
Steady-state fluorescence spectra of pyrene probe in the solutions of nanostructures were recorded with a double-grating excitation and a single-grating emission spectrofluorometer (Fluorolog-3, model FL3-21, Jobin Yvon-Spex) at room temperature $\left(25^{\circ} \mathrm{C}\right)$. Excitation wavelength was $\lambda=335 \mathrm{~nm}$ for pyrene and emission spectra were recorded in the region $350-600 \mathrm{~nm}$, with an increment of $1 \mathrm{~nm}$, using an integration time of $0.5 \mathrm{~s}$. Slit openings of $1 \mathrm{~nm}$ were used for both the excitation and the emitted beams. The dispersions containing the probe were left to equilibrate in the dark at $4^{\circ} \mathrm{C}$ for $24 \mathrm{~h}$ before the measurements. The intensity ratio of peak 1 to peak 3 , $I_{1} / I_{3}$, serves as a measure of the micropolarity, i.e. larger $I_{1} / I_{3}$ ratio designates higher polarity of the surrounding medium. The microfluidity was estimated from the fluorescence intensity ratio $I_{E} / I_{M}$, where $I_{E}$ and $I_{M}$ are the fluorescence intensities of pyrene excimer and monomer, respectively. $\mathrm{I}_{\mathrm{E}}$ and $\mathrm{I}_{\mathrm{M}}$ were measured at emission wavelengths 480 and $372 \mathrm{~nm}$, respectively. The fluorescence intensity ratio $\mathrm{I}_{\mathrm{E}} / \mathrm{I}_{M}$ offers an index of microfluidity, because the ratio $\mathrm{I}_{\mathrm{E}} / \mathrm{I}_{\mathrm{M}}$ is proportional to the frequency of collisions of pyrene molecules, namely the ability to form excimer. Typically, larger values of $\mathrm{I}_{\mathrm{E}} / \mathrm{I}_{\mathrm{M}}$ imply a larger microfluidity.

\section{Results and Discussion}

Physicochemical characterization of QNPHOSEO:PCK3145 complexes.

The complexation process between the QNPHOSEO polyelectrolyte and PCK3145 at $\mathrm{pH}=7.00$ and at $\mathrm{pH}=7.40$ was first investigated by means of dynamic light scattering. It should be noted that PBS $(\mathrm{pH}=7.40)$ was chosen as dispersion medium because the $\mathrm{pH}$ and the ionic strength of PBS resembles the conditions met within the human body. At $\mathrm{pH}=7.00$ the electrostatic interactions of the system are expected to be strong, since the QNPHOSEO polyelectrolyte block carries two positively charged 
groups per functionalized monomeric unit and PCK3145 has a net negative charge of -4. The obtained results from DLS measurements at $90^{\circ}$ regarding the values of the light scattering intensity, $\mathrm{I}_{90}$ (corrected for the concentration increase) and hydrodynamic radius, $R_{h}$, are shown in Figures 2 (a) and (d), as function of the peptide concentration, $\mathrm{C}_{\mathrm{PCK} 3145}$, in the solutions of the complexes. The concentration of QNPHOSEO copolymer is kept constant throughout the series of aqueous solutions of different ionic strength investigated. DLS results at low ionic strength $(0.01 \mathrm{M})$ show that all solutions exhibit a main peak at high $R_{h}$ values $(\sim 40 \mathrm{~nm})$, which apparently corresponds to the formed mixed aggregates and a significantly smaller one at lower $R_{h}$ values, which most probably denotes the presence of a small number of free unimer diblock copolymer chains in solution. The values of the scattering intensity, I90, which is proportional to the mass of the species in solution, increased gradually as

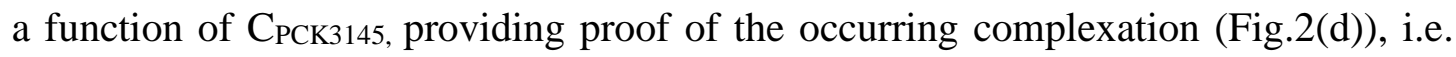
the mass of the complexes increases as $\mathrm{C}_{\mathrm{PCK} 3145}$ increases. As peptide concentration increases each polyelectrolyte chain interacts with an increasing number of peptide molecules, the degree of charge neutralization becomes higher and the size distribution of the complexes decreases, especially in the lowest ionic strength (Becker et al., 2012). In contrast $\mathrm{I}_{90}$ (and mass of the complexes) remains almost constant in the case of PBS solutions. $\zeta$ - potential decreases in absolute value as the concentration of the peptide increases, or equivalently the effective positive charge of the complexes reduces as a function of the peptide concentration. The values of $R_{g} / R_{h}$ were also calculated (Fig 2.(e)). This ratio is sensitive to the shape of particles in solution and can be used as a rough estimate of the internal morphology of the particle. This is based on the notion that $\mathrm{R}_{\mathrm{g}}$ is a measure of the mass density distribution around the center of the structure, while $\mathrm{R}_{\mathrm{h}}$ defines the outer dimensions 
of the particle. According to Burchard (1983), the ratio $R_{g} / R_{h}$ takes the values of 0.775 for a hard uniform sphere and 1.0 for vesicles with thin walls, while values of 1.3 to 1.5 indicate a random coil (loose) conformation in the case of macromolecular chains. In the present case, the values $\mathrm{R}_{\mathrm{g}} / \mathrm{R}_{\mathrm{h}}$ are near 1.00 for QNPHOSEO:PCK3145 at PBS, and these observations may indicate a more well-defined hollow sphere (vesicle like) structure for the aggregates (Fig 2.(e)) or a rather low density full spherical structure. On the other hand, the values $\mathrm{R}_{\mathrm{g}} / \mathrm{R}_{\mathrm{h}}$ indicate open (low density) spherical structures for aggregates in the $\mathrm{pH}=7.00$ buffer (Fig 2.(e)). These differences may be a result of the differences in the salinity of the media.

It is important to characterize the physicochemical properties of the nanostructures in biological media, like FBS, because interaction with proteins of the medium is expected to alter the physicochemical properties of the nanostructures, thereby affecting their stability and clearance properties (Arnida, Janát-Amsbury et al., 2011). The size of complexes in biological medium (FBS) was not increased significantly (Figure 3). This observation indicates that QNPHOSEO copolymer imparts stealth properties and stability in the complexes, due to the presence of PEO chains that shield the complexes. A shift of $\zeta$-potential to negative values is observed presumably due to some binding of FBS proteins, which can alter the nanoparticle's effective size and surface properties (the main protein component of FBS is albumin which carries a negative charge at physiological conditions) (Law et al., 1986; Sabín et al., 2009; Pippa et al., 2012a,b).

\section{Effect of ionic strength}

The increase of the ionic strength in the solutions of the complexes induces charge screening and weakening of the electrostatic interactions, so it is expected to greatly influence the solution behavior and structure/morphology of the performed 
complexes. In order to investigate this effect, DLS/SLS measurements as a function of the added $\mathrm{NaCl}$ concentration were conducted, and the resulting $\mathrm{I}_{90}$ (corrected for the difference in concentration) and $\mathrm{R}_{\mathrm{h}}$ values for representative solutions at low and high

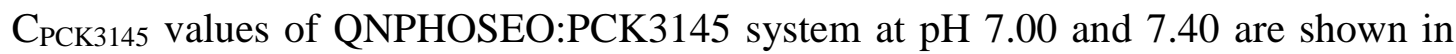
Figs. 4. and 5. The hydrodynamic radius of the complexes, as a function of PCK3145 concentration, remained more or less unaffected in the case of PBS buffer (Fig. 5(a)), while their morphology changed and more compact structures are observed (Fig. 5(c)) (Karayianni and Pispas, 2012).

At pH 7.00 the solutions of the complexes exhibit a different response to the increase of the ionic strength, apparently due to the particular structure of the formed complexes in each solution (Fig. 4.) We recall that at low $\mathrm{C}_{\text {PCK3145 values the number }}$ of interacting peptide molecules per polyelectrolyte chain is rather small, while at high $\mathrm{C}_{\mathrm{PCK} 3145}$ values the formed complexes are characterized by rather large number of interacting peptide molecules per polyelectrolyte chain (Karayianni et al., 2011). The aggregation of the complexes is marked by a subsequent gradual increase of their size (Fig. 4a). Respectively, an abrupt increase of the mass of the complexes is observed at higher $\mathrm{C}_{\mathrm{PCK} 3145}$ upon addition of the salt at both pHs (Figs. $4 \mathrm{~b}$ and $5 \mathrm{~b}$ ). It seems that in this case the increase of the ionic strength results to a secondary aggregation, because the number of QNPHOSEO chains in respect to PCK3145 is small.

In general, it was determined that the increase of the ionic strength in the solutions of the complexes eventually causes the aggregation of the preformed complexes. This effect arises from the induced charge screening that weakens the electrostatic interactions of the systems. Of course, one should keep in mind that the weakening of 
the electrostatic interactions enhances the role of the existing hydrophobic interactions in the system (QNPHOSEO has a hydrophobic backbone and side groups).

Fluorescence spectroscopy has been utilized in an attempt to extract information on the internal structure and microenvironment of nanostructures in aqueous solutions. The ratio $I_{1} / I_{3}$ in the fluorescence emission spectrum of pyrene is used as a measure of the polarity of the environment of the pyrene probe. In aqueous or similarly polar environment this ratio is found between 1.6 and 1.9. High values of the $I_{1} / I_{3}$ ratio were observed for the complexes (Table 1), which interestingly remained unaffected as the PCK3145 concentration increased. The behavior should be related to the significantly hydrophilic nature of the QNPHOSEO copolymer and that of the complexes (Mountrichas et al., 2006; Mountrichas and Pispas, 2007; Mantzaridis et al., 2009; Stepanek et al., 2011).

The physicochemical characteristics of liposomal and dendritic nanoparticles incorporating tigapotide.

Physicochemical characteristics of different liposomal formulations in PBS are presented in Table 2. The incorporation of PCK3145 leads to increased size of liposomes, especially for the nanocarriers incorporating SA (Table 3). The decrease of $\zeta$-potential values indicates that there is an electrostatic attraction between the positive charge of liposomal membrane and the PCK3145. In our opinion, this electrostatic attraction is the driving force for the peptide's encapsulation attachment in the liposomal internal and external surface. For this reason, we observed a statistically significant increase of the size of liposomes DPPC:SA:PCK3145 (9:0.2:1 molar ratio) and EggPC:SA:PCK3145 (9:0.2:1 molar ratio), in comparison to neat liposomal nanocarriers (Table 2). Temporal colloidal stability of the initially formed chimeric 
nanostructures in PBS was investigated (Fig. 6). Generally, size and size distribution control is of a great importance in preparing liposomal formulations, because liposomal size can modulate the biological stability, the Adsorption, Distribution, Metabolism, Excretion and Toxicity (ADMET) profile of encapsulated bioactive compound, the biopharmaceutical/pharmacokinetic behavior and the capture mechanism by macrophages (Amado et al., 2009; Vallianatou and TsantiliKakoulidou, 2013). The stability study over time for all liposomal formulations incorporating PCK3145 was performed by measuring the nanocarrier size and size distribution for a period up to two weeks. The liposomal suspensions were kept under dark at $4{ }^{\circ} \mathrm{C}$. The two liposomal nanocarriers incorporating the tigapotide, without SA, in PBS were found to retain their original physicochemical characteristics for at least a week (Fig. 6). No sedimentation was observed, while their average size did not increase significantly, for DPPC:PCK3145(9:0.2 molar ratio) and EggPC:PCK3145 (9:0.2 molar ratio), probably due to the existence of hydration forces (Ohki and Ohshima, 1999; Ohki and Alnord, 2000; Heutault et al., 2003). On the other hand, the size of DPPC:SA:PCK3145(9:1:0.2 molar ratio) and EggPC:SA:PCK3145 (9:1:0.2 molar ratio) decreased significantly one day after the preparation of liposomal nanoparticles (Fig. 6) and remained unaffected up to a week. Then, an increase of the $\mathrm{R}_{\mathrm{h}}$ of these liposomal formulations was observed. In our point of view this unexpected behavior was due to the release of PCK3145 from the DPPC:SA (9:0.2 molar ratio) and EggPC:PCK3145 (9:0.2 molar ratio) liposomal nanocarriers and their size reduced significantly. After, the release of tigapotide the liposomal nanocarriers aggregated due to the absence of electrostatic repulsion, as indicated from $\zeta$-potential values (Table 2) (Heutault et al., 2003). 
Furthermore, we examined the complexation process between tigapotide and PAMAM-G4 dendrimer in PBS by two different protocols via $\zeta$-potential as they were presented previously. The core of PAMAM is a diamine (commonly ethylenediamine), which is reacted with methyl acrylate, and then another ethylenediamine to make the generation-0 (G-0) PAMAM by click chemistry. Low generation dendrimers can be thought of as flexible molecules with no appreciable inner regions, while medium sized dendrimers do have internal space that is essentially separated from the outer shell of the dendrimer (Tomalia et al., 1985). Dendrimers are utilized for their tertiary amine groups at the branching points within the dendrimer. Due to their relatively high pKa value (pKa 9.2), the primary amine groups undergo protonation at neutral $\mathrm{pH}$ so that there is a high density of positive charges on the surface of PAMAM dendrimers, which enables the formation of nanosized complexes with negatively charged peptides and proteins through electrostatic interactions (Choi et al., 2006; Ainalem et al., 2010; Jin et al., 2011). Due to their low $\mathrm{pKa}(\mathrm{pKa} 6.7)$, tertiary amine groups in the PAMAM interior are protonated only at acidic $\mathrm{pH}$ environments (Jin et al., 2011). According to the recent literature, the binding mode of a bioactive compound to the dendrimer was found to be dependent not only on dendrimer's physicochemical characteristics (i.e. size, pKa, nature of functional groups) and structure of the biomolecules, but also on dendrimer generation, core structure and surface charge of dendrimer (D' Emanuele and Attwood, 2005; Gupta et al., 2006; Maingi et al., 2012). For the last reason, we chose $\zeta$-potential in order to extract information on the complexation process of these biomaterials. The $\zeta$-potential values of the PAMAM-G4:PCK complexes in PBS at different molar ratios and different preparation protocols are presented in Table 4. The $\zeta$-potential of PAMAM-G4 dendrimers as well as of PCK3145 was found near 
zero in PBS (Table 4). The $\zeta$-potential was not changed significantly by the addition of PCK3145 solutions into PAMAM-G4 dendrimer solutions (Table 3A). On the other hand, the addition of PAMAM-G4 dendrimer solution into PCK3145 solution caused a shift from slightly negative to slightly positive values (Table 3B). It is supposed that the relatively low positive zeta-potential of mixed dendritic nanostructures comparing to free tigapotide is due to the imperfect complexation efficiency of peptide moiety on the surface of dendrimer as mentioned above, resulting to the loss of negative charge of the PCK3145 at neutral $\mathrm{pH}$. In our opinion, these observations could be a first indication that the preparation protocol affects the complexation of the peptide into dendritic nanoparticles. The structure of dendritic nanoparticles incorporating tigapotide is presented in Scheme 1. Due to its relatively large size PCK peptide is difficult to be incorporated in the dendrimer's interior. PCK is expected to interact with the surface amine groups and to be located close to the dendrimer surface.

\section{Conclusions}

This investigation relates to novel nanocarriers of tigapotide including polymer, lipid and dendrimer based nanoparticles and their use in the treatment of disease. These nanocarrier compositions are expected to maximize the advantages of the peptide delivery process, and consequently the biological properties (i.e. antitumoral) of tigapotide. Dynamic (DLS), static (SLS) and electrophoretic (ELS) light scattering were used to examine the size, the size distribution, the z-potential, as well as the structural characteristics of the carriers in aqueous and biological media. The behavior of the nanosystems greatly depends on the nature of the components and their ratio. This study provides interesting and useful new insights into the interaction mechanism between oppositely charged block polyelectrolyte aggregates with stealth 
properties and therapeutic peptides. The encapsulation of this antitumor peptide is higher into liposomes incorporating stearylamine, as indicated from the liposomal formulations' physicochemical characteristics. To the best of the authors' knowledge this is the first report on the encapsulation of tigapotide in different nanoparticulate carriers. The results of our study contribute to the overall scientific efforts to prepare efficient carriers for tigapotide and could be useful in order to develop nanocarriers with increased efficacy, safety and tolerability. The prepared nanocarriers can disclose the pharmacokinetic reality of behavior of tigapotide and improve its therapeutic value and side effects. This is because of the interdependence of particle size distribution and physicochemical characteristics, coupled with the beneficial effects of different biomaterials on biological and pharmacokinetic processes.

\section{Acknowledgements}

Authors acknowledge financial support of the work by the NANOMACRO 1129 project which is implemented in the framework of the Operational Program "Education and Life-long Learning" (Action "ARISTEIA I") and it is co-funded by the European Union (European Social Fund) and by national funds. 


\section{References}

Al-Tahami K, Singh J (2007) Smart polymer based delivery systems for peptides and proteins. Recent Pat Drug Deliv Formul 1:65-71

Ainalem ML, Campbell RA, Khalid S, Gillams RJ, Rennie AR, Nylander T (2010) On the ability of PAMAM dendrimers and dendrimer/DNA aggregated to penetrate POPC model biomembranes. J Phys Chem B 114(21):7229-44.

Amado E, Blume A, Kressler J (2009) Novel non-ionic block copolymers tailored for interaction with phospholipids. React Funct Polym 69:450-456

Annabi B, Bouzeghrane M, Currie JC, Hawkins R, Dulude H, Daigneault L, Ruiz M, Wisniewski J, Garde S, Rabbani SA, Panchal C, Wu JJ, Béliveau R (2005) APSP94derived peptide PCK3145 inhibits MMP-9 secretion and triggers CD44 cell surface shedding: implication in tumor metastasis. Clin Exp Metastasis 22:429-439

Annabi B, Bouzeghrane M, Currie JC, Dulude H, Daigneault L, Garde S, Rabbani SA, Panchal C, Wu JJ, Béliveau R (2006) Inhibition of MMP-9 secretion by antimetastatic PSP-94derived peptide PCK3145 requires cell surface laminin receptor signaling. Anticancer Drugs 17:429-438

Asthana A, Chauhan AS, Diwan PV, Jain NK (2005) Poly(amidoamine) (PAMAM) dendritic nanostructures for controlled site-specific delivery of acidic anti-inflammatory active ingredient AAPA PharmSciTech 6(3):E536-42

Arnida Janát-Amsbury MM, Ray A, Peterson CM, Chandehari H (2011) Geometry and surface characteristics of gold nanoparticles influence their distribution and uptake by macrophages. Eur J Pharm Biopharm 77:417-423

Aulenta F, Hayes W, Rannard S (2003) Dendrimers a new class of nanoscopic containers and delivery devices. Eur Polym J 39:1741-1771

Bangham AD, Standish MM, Watkins JC (1965) Diffusion of univalent ions across the lamellae of swollen phospholipids. J Mol Biol 13:238-252

Becker AL, Henzler K, Welsch N, Ballauff M, Borisov O (2012) Proteins and polyelectrolytes: A charged relationship. Curr Opin Colloid Interface Sc 17:90-96

Bonicelli MG, Giasanti L, Ierino M, Mancini G (2011) Interaction of cationic liposomes with cell membrane models. J Colloid Interface Sci 355:1-8

Burchard W (1983) Static and dynamic light scattering from branched polymers and biopolymers. Adv Polym Sci 48:1-124

Capriotti AL, Garacciolo G, Gavaliere C, Foglia P, Pozzi D, Samperi R, Laganá A (2012) Do plasma proteins distinguish between liposomes of varying charge density? J Proteomics 75:1924-32 
Chauhan AS, Diwan PV, Jain NK, Tomalia DA (2009) Unexpected in vivo antiinflammatory activity observed for simple, surface functionalized poly(amidoamine) dendrimers. Biomacromolecules 10:1195-1202

Cheng Y, Xu Z, Ma M, Xu T (2008) Dendrimers as drug carriers: applications in different routes of drug administration. J Pharm Sci 97:123-143

Choi YS, Cho TS, Kim JM, Han SW, Kim SK (2006) Amine terminated G-6 PAMAM dendrimer and its interaction with DNA probed by Hoeschst 33258. Biophys Chem 121(2):142-149

Cloninger M (2002) Biological application of dendrimers. Curr Opin Chem Biol 6: 742-748

Crommelin DJ, Florence AT (2013) Towards more effective advanced drug delivery systems. Int $\mathrm{J}$ Pharm In press

Delgado AV, Conzález-Caballero F, Hunter RJ, Koopal LK, Lyklema J (2007) Measurement and interpretation of electrokinetic phenomena. J Colloid Interface Sci 309:194-224

D' Emanuele A, Attwood D (2005) Dendrimer-drug interactions. Adv Drug Deliv Rev 57:2147-2162

DeMattei CR, Huang B, Tomalia DA (2004) Designed dendrimer syntheses by selfassembly of single-site, ssDNA functionalized dendrons. Nano Letters 4:771-777

Demetzos C (2006) Dendrimers as drug carriers: a new approach to increase the potential of bioactive natural products. Natural Product Communications (NPC) 7:593-600

Eichman J, Bielinska A, Kukowska-Latallo J, Donovan B, Baker J (2001) In: Frechet J, Tomalia D (Eds.) Dendrimers and other Demdritic Polymers. John Wiley \& Sons, Chisester, pp. $441-462$

Esfand R, Tomalia DA (2001) Poly(amidoamine) (PAMAM) dendrimers: from biomimicry to drug delivery and biomedical applications. Drug Discov Today 6:427436.

Gardikis K, Tsimplouli C, Dimas K, Micha-Screttas M, Demetzos C (2010) New chimeric advanced Drug Delivery nano System (chi-aDDnSs) as doxorubicin carriers. Int J Pharm 402:231-237

Gardikis K, Fessas D, Signorelli M, Dimas K, Tsimplouli C, Ionov M, Demetzos C (2011) A new chimeric drug delivery nano system (chi-aDDnS) composed of PAMAM-G4 G 3.5 dendrimer and liposomes as doxorubicin's carrier. In vitro pharmacological studies. J Nanosci Nanotechnol 5:3764-3772 
Gregoriadis G, Wills EJ, Swain CP, Tavill AS (1974) Drug-carrier potential of liposomes in cancer chemotherapy. Lancet 1:1313-1316

Gupta U, Agashe HB, Asthana A, Jain NK (2006) Dendrimers: novel polymeric nanoarchitectures for solubility enhancement. Biomacromolecules 7:649-658

Haladjova E, Rangelov S, Tsvetanov CB, Pispas S (2012) DNA encapsulation via nanotemplates from cationic block copolymer micelles. Soft Matter 8: 2884-2889

Hartig SM, Greene RR, DasGupta J, Carlesso G, Dikov MM, Prokop A, Danidson JM (2007) Multifunctional nanoparticulate polyelectrolyte complexes. Pharm Res 24:2353-2369.

Heutault B, Saulnier P, Pech B, Proust JE, Benoit JP (2003) Physico-chemical stability of colloidal lipid particles. Biomaterials 24:4283-4300

Hofheinz RD, Gnad-Vogt SU, Beyer U, Hochhaus A (2005) Liposomal encapsulated anti-cancer drugs. Anticancer Drugs 16:691-707

Jevprasesphant R, Penny J, Attwood D, D'Emanuele A (2004) Transport of dendrimer Nanocarriers through epithelial cells via the transcellular route. J Controlled Release 97: 259267

Jin Gw, Koo H, Nam K, Kim H Lee S, Park JS, Lee Y (2011) PAMAM dendrimer with a 1,2 -diaminoethane surface facilitates endosomal escape for enhances pDNA delivery. Polymer 52:339-346

Kapoor M, Burgess DJ, Patil SD (2012) Physicochemical characterization techniques for lipid based delivery syatems for siRNA. Int J Pharm 427:35-57

Kaditi E, Mountrichas G, Pispas S, Demetzos C (2012) Block copolymers for drug delivery nano systems (DDnSs). Curr Med Chem 19:5088-5100

Karayianni M, Pispas S, Chryssikos GD, Gionis V, Giatrellis S, Nounesis G (2011) Complexation of lysozyme with poly(sodium (sulfamate-carboxylate)isoprene). Biomacromolecules 12:1697-1706

Karayianni M, Pispas S (2012) Complexation of stimuli-responsive star-like amphiphilic block polyelectrolyte micelles with lysozyme. Soft Matter 8:8758-8769.

Law SL, Lo WY, Pai SH, The GW, Kou FY (1986) The adsorption of bovine serum albumin by liposomes. Int J Pharm 32:237-241

Maingi V, Kumar MV, Maiti PK (2012) PAMAM dendrimer-drug interactions: effect of $\mathrm{pH}$ on the binding and release pattern. J Phys Chem B 116:4370-4376 
Mantzaridis C, Mountrichas G, Pispas S (2009) Complexes between high charge density cationic polyelectrolytes and anionic single- and double-tail surfactants. J Phys Chem B 113:7064-7070

Menjoge AR, Kannan RM, Tomalia DA (2010) Dendrimer-based drug and imaging conjugates: design considerations for nanomedical applications. Drug Discov Today 15:171-185

Mountrichas G, Mantzaridis C, Pispas S (2006) Well-defined flexible polyelectrolytes with two cationic sites per monomeric unit. Macromol Rapid Comm 27:289-294

Mountrichas G, Pispas S (2007) Novel double hydrophilic block copolymers based on poly(p-hydroxystyrene) derivatives and poly(ethylene oxide). J Polym Sci Part A: Polym. Chem 45:5790-5799

Ohki S, Ohshima H (1999) Interaction and aggregation of lipid vesicles (DLVO theory versus modified DLVO theory). Colloids Surf B: Biointerfaces 14:27-45

Ohki S, Arnold K (2000) A mechanism for ion-induced lipid fusion. Colloids Surf. B: Biointerfaces 18:83-97

Pippa N, Pispas S, Demetzos C (2012a). The delineation of the morphology of charged liposomal vectors via a fractal analysis in aqueous and biological media: physicochemical and self-assembly studies. Int J Pharm 437:264-274.

Pippa N, Pispas S, Demetzos C (2012b). The fractal hologram and elucidation of the structure of liposomal carriers in aqueous and biological media. Int J Pharm 430:6573

Pippa N, Kaditi E, Pispas S, Demetzos C (2013a) PEO-b-PCL/DPPC chimeric nanocarriers: self-assembly aspects in aqueous and biological media and drug incorporation. Soft Matter 9:4073-4082

Pippa N, Merkouraki M, Pispas S, Demetzos C (2013b) DPPC:MPOx chimeric advanced Drug Delivery nanosystems (chi-aDDnSs): physicochemical and structural characterization, stability and drug release studies. Int J Pharm 450:1-10

Pippa N, Kaditi E, Pispas S, Demetzos C (2013c) DPPC/poly(2-methyl-2-oxazoline)grad-poly(2-phenyl-2-oxazoline) chimeric nanostructures as potential drug nanocarriers. J Nanopart Res 15:1685

Pippa N, Psarommati F, Pispas S, Demetzos C. (2013d) The shape/morphology balance: A study of stealth liposomes via fractal analysis and drug encapsulation. Pharm Res In press 
Pispas S (2007) Complexes of lysozyme with sodium (sulfamatecarboxylate)isoprene/ethylene oxide double hydrophilic block copolymers. J Polym Sci Part A: Polym Chem 45:509-520

Reis CP, Ribeiro AJ, Veiga F, Neufeld RJ, Damgé C (2008) Polyelectrolyte biomaterial interactions provide nanoparticulate carrier for oral insulin delivery. Drug Deliv 15:127-139

Rowland M, Noe CR, Smith DA, Tucker GT, Crommelin DJ, Peck CC, Rocci ML Jr, Basançon L, Shah VP (2012) Impact of the pharmaceutical sciences on health care: a reflection over the past 50 years. J Pharm Sci 101:4075-4099

Ruozi B, Forni F, Battini R, Vandelli MA (2003) Cationic liposomes for gene transfection. J Drug Target 11:407-414

Sabín J, Prieto G, Ruso JM, Messina PV, Salgado FJ, Nogueira M, Costas M, Sarmiento F (2009) Interactions between DMPC liposomes and the serum blood proteins HSA and IgG. J Phys Chem B 113:1655-1661

Sadekar S, Ghandehari H (2012) Transepithelial transport and toxicity of PAMAM denedrimers: implications for oral drug delivery. Adv Drug Deliv Rev 64(6):571-588

Shukeir N, Arakelian A, Chen G, Garde S, Ruiz M, Panchal C, Rabbani SA (2004) A synthetic 15mer peptide (PCK3145) derived from prostate secretory protein can reduce tumor growth, experimental skeletal metastases, and malignancy-associated hypercallcemia. Cancer Res 64:5370-5377

Slingerland M, Guchelaar HJ, Gelderblom H (2012) Liposomal drug formulations in cancer therapy: 15years along the road. Drug Discov Today 17:160-166

Stepanek M, Matejicek P, Prochazka K, Filippov SK, Angelov B, Slouf M, Mountrichas G, Pispas S (2011) Polyelectrolyte-surfactant complexes formed by poly-[3,5-bis(trimethylammoniummethyl)-4-hydroxystyrene iodide]-blockpoly(ethylene oxide) and sodium dodecyl sulfate in aqueous solutions. Langmuir 27: 5275-5281

Svenson S, Tomalia DA (2005) Dendrimers in biomedical applications-reflections on the field. Adv Drug Deliv Rev 57(15):2106-29

Tomalia DA, Baker H, Dewald J, Hall M, Kallos G, Martin S, Roeck J, Ryder J, Smith P (1985) A new class of polymers: starburst-dendritic macromolecules. Polymer Journal $17: 117-132$

Tomalia DA, Reyna LA, Svenson S (2007) Dendrimers as multi-purpose nanodevices for oncology drug delivery and diagnostic imaging. Biochem Soc Trans 35:61-67

Tomalia DA (2009) In quest of a systematic framework for unifying and defining nanoscience. J Nanopart Res 11:1251-1310 
Torchilin VP (2004) Targeted polymeric micelles for delivery of poorly soluble drugs. Cell Mol Life Sci 61:2549-2559

Torchilin VP (2007) Micellar Nanocarriers: Pharmaceutical perspectives. Pharm Res 21:1-15

Vallianatou T, Tsantili-Kakoulidou A (2013) In silico methods of ADME(T) prediction: a brief review. Pharmakeftiki In press

Varkouhi AK, Mountrichas G, Schiffelers RM, Lammers T, Storm G, Pispas S, Hennik WE (2012) Polyplexes based on cationic polymers with strong nucleic acid binding properties. Eur J Pharm Sci 45:459-466

Wu SY, McMillan NAJ (2009) Lipidic systems for in vivo siRNA delivery. The AAPS Journal 11:639-652 


\section{Figures}

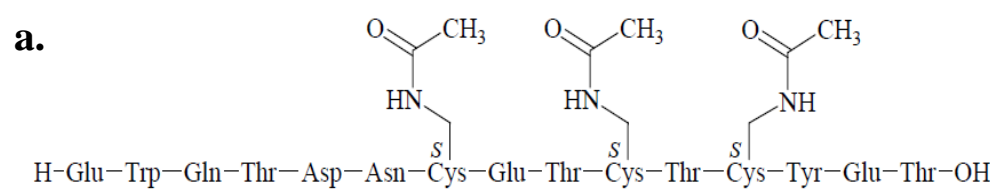

b.<smiles>CCC(C)c1cc(C[N+](C)(C)C)c(O)c(C[N+](C)(C)C)c1</smiles>

c.

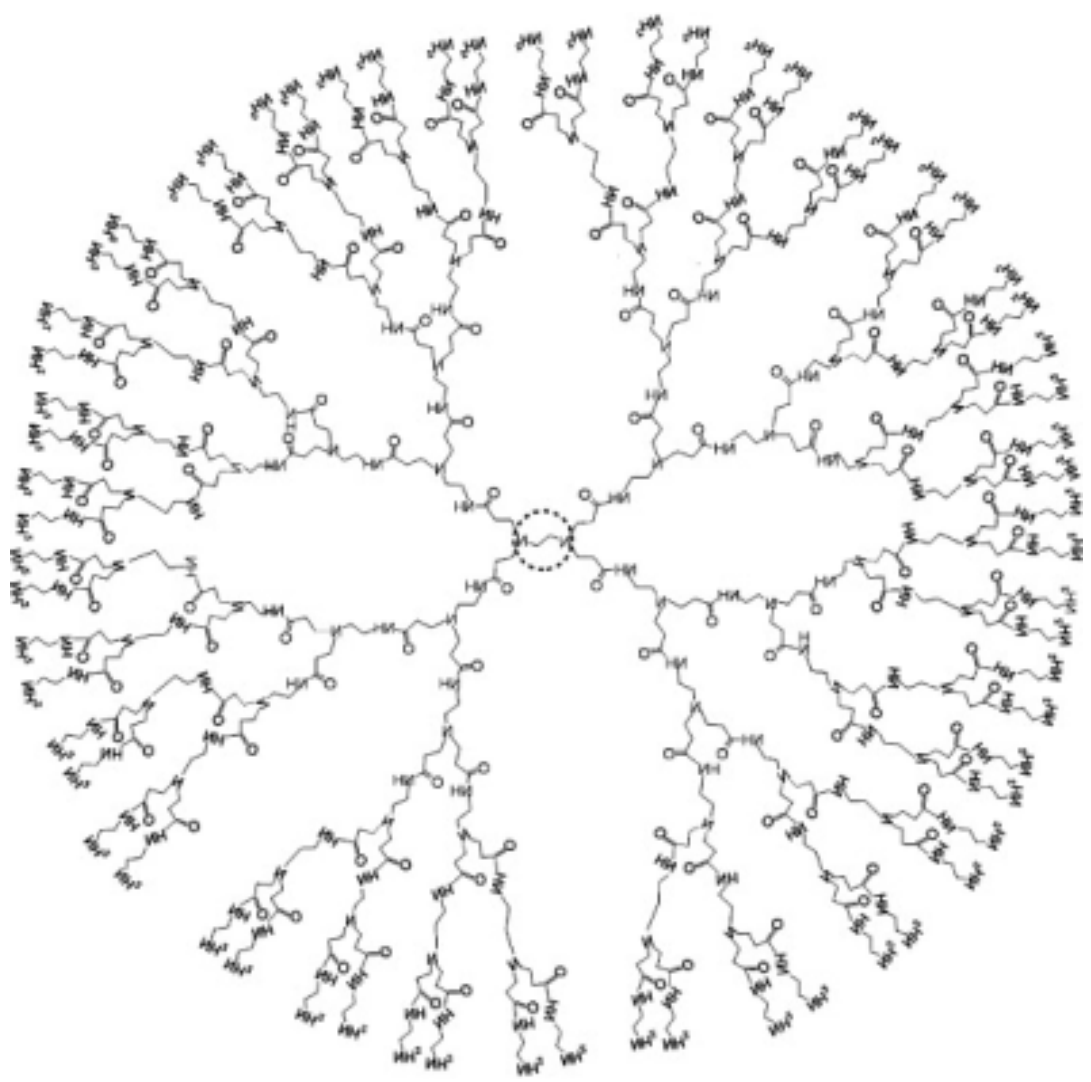

Fig. 1. Molecular structure of a. tigapotide (PCK 3145), b. QNPHOSEO-9 polyelectrolyte block copolymer (the degrees of polymerization are $\mathrm{m}=162$ and $\mathrm{n}=334$ ) and c. PAMAM G-4 dendrimer. 

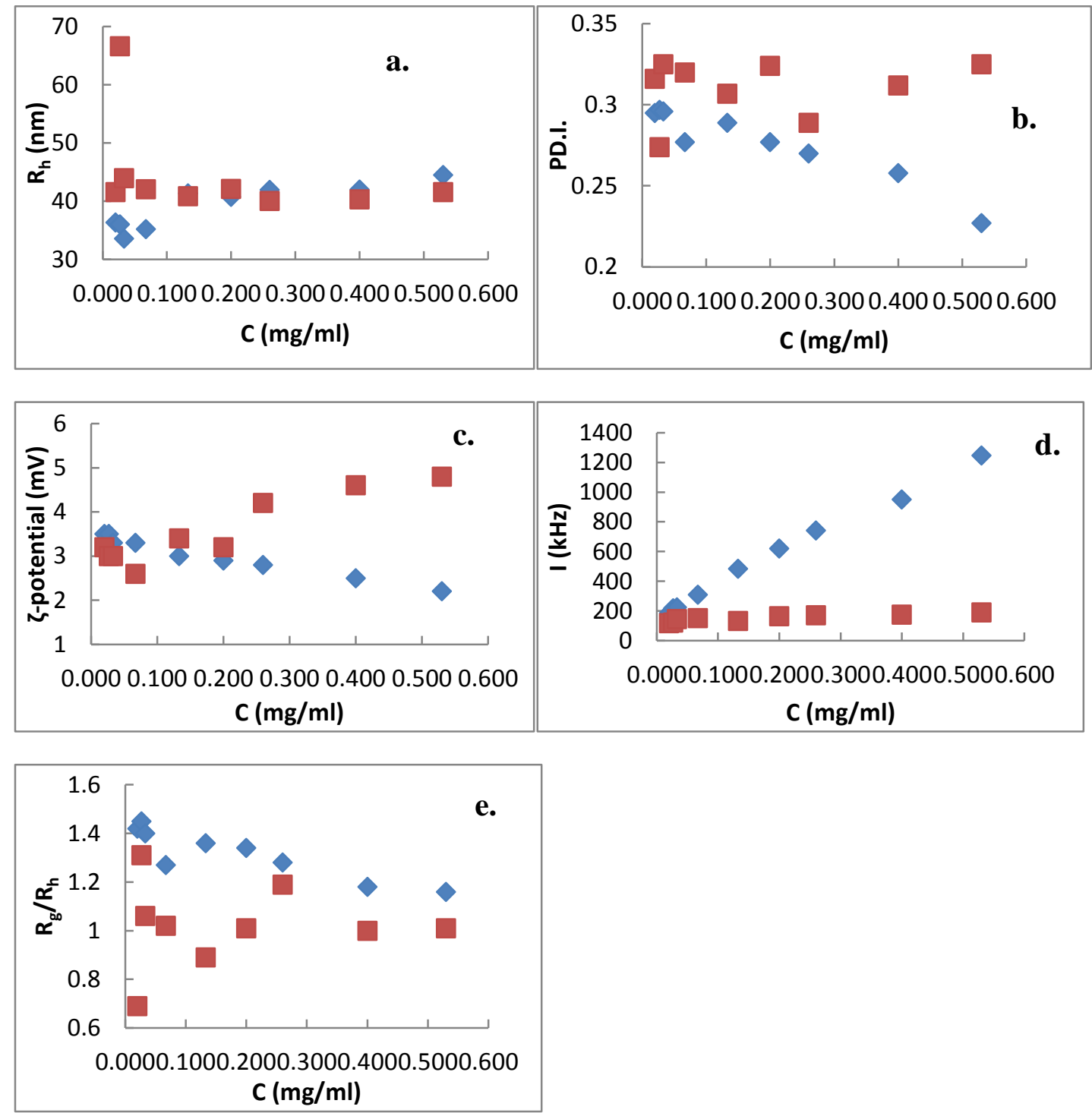

Fig. 2. (a) Hydrodynamic Radius, $\mathrm{R}_{\mathrm{h}}$, (b) Polydispersity Index, (PD.I.), (c) $\zeta$ potential, (d) light scattering intensity at $90^{\circ}$, I, and (e) $\mathrm{Rg} / \mathrm{R}_{\mathrm{h}}$ as a function of CPCK3145, for the solutions of QNPHOSEO:PCK3145 system at $\mathrm{pH}=7.00$ and $0.01 \mathrm{M} \mathrm{NaCl}$ (blue points) and at $\mathrm{pH}=7.40$ and $0.154 \mathrm{M} \mathrm{NaCl}$ (red points). 

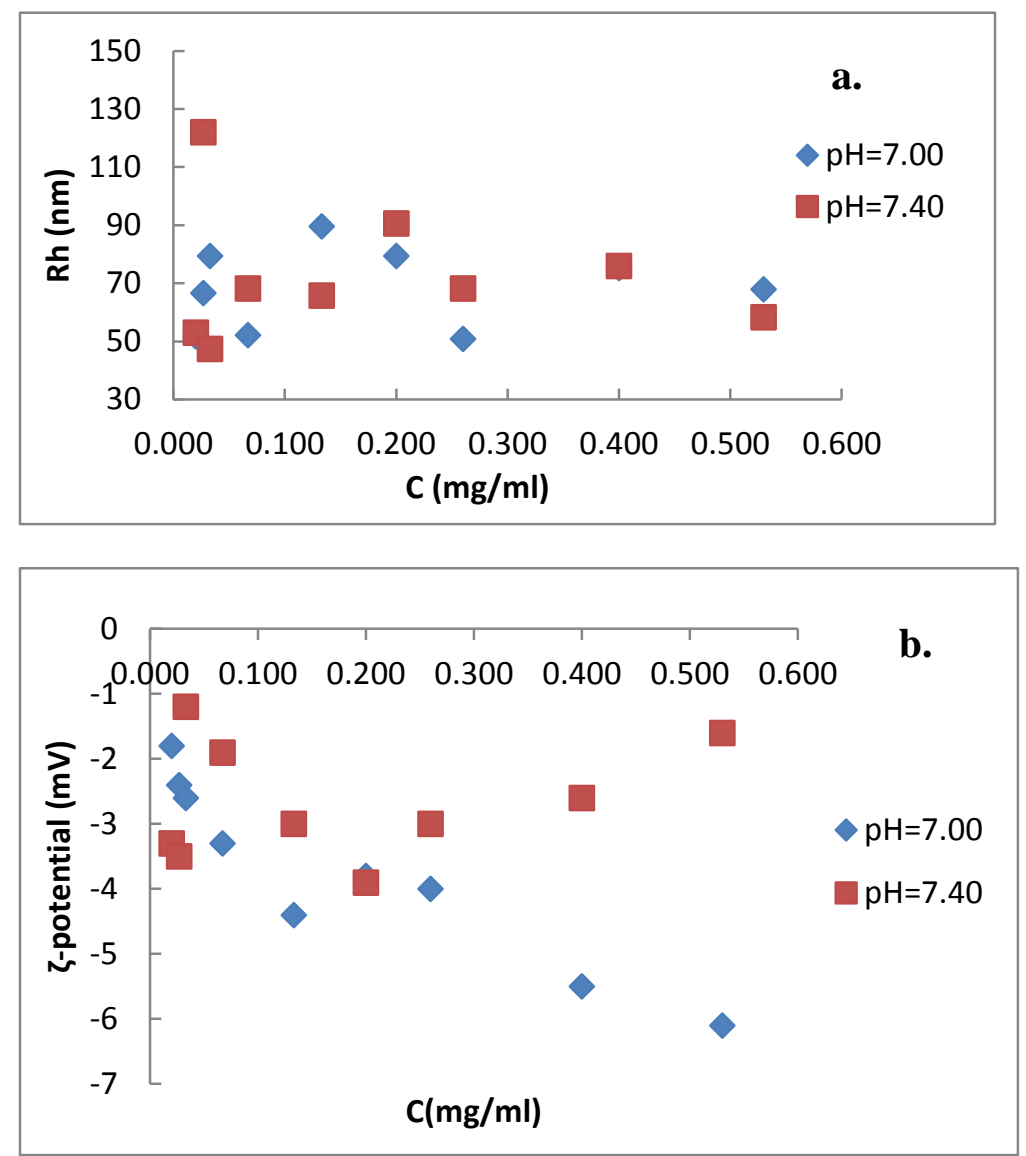

Fig. 3. (a) Hydrodynamic Radius, $\mathrm{R}_{\mathrm{h}}$ and (b) $\zeta$-potential, as a function of $\mathrm{C}_{\mathrm{PCK} 3145}$, for the solutions of QNPHOSEO:PCK3145 system at $\mathrm{pH}=7.00$ and $0.01 \mathrm{M} \mathrm{NaCl}$ (blue points) and at $\mathrm{pH}=7.40$ and $0.154 \mathrm{M} \mathrm{NaCl}$ (red points) at FBS. 

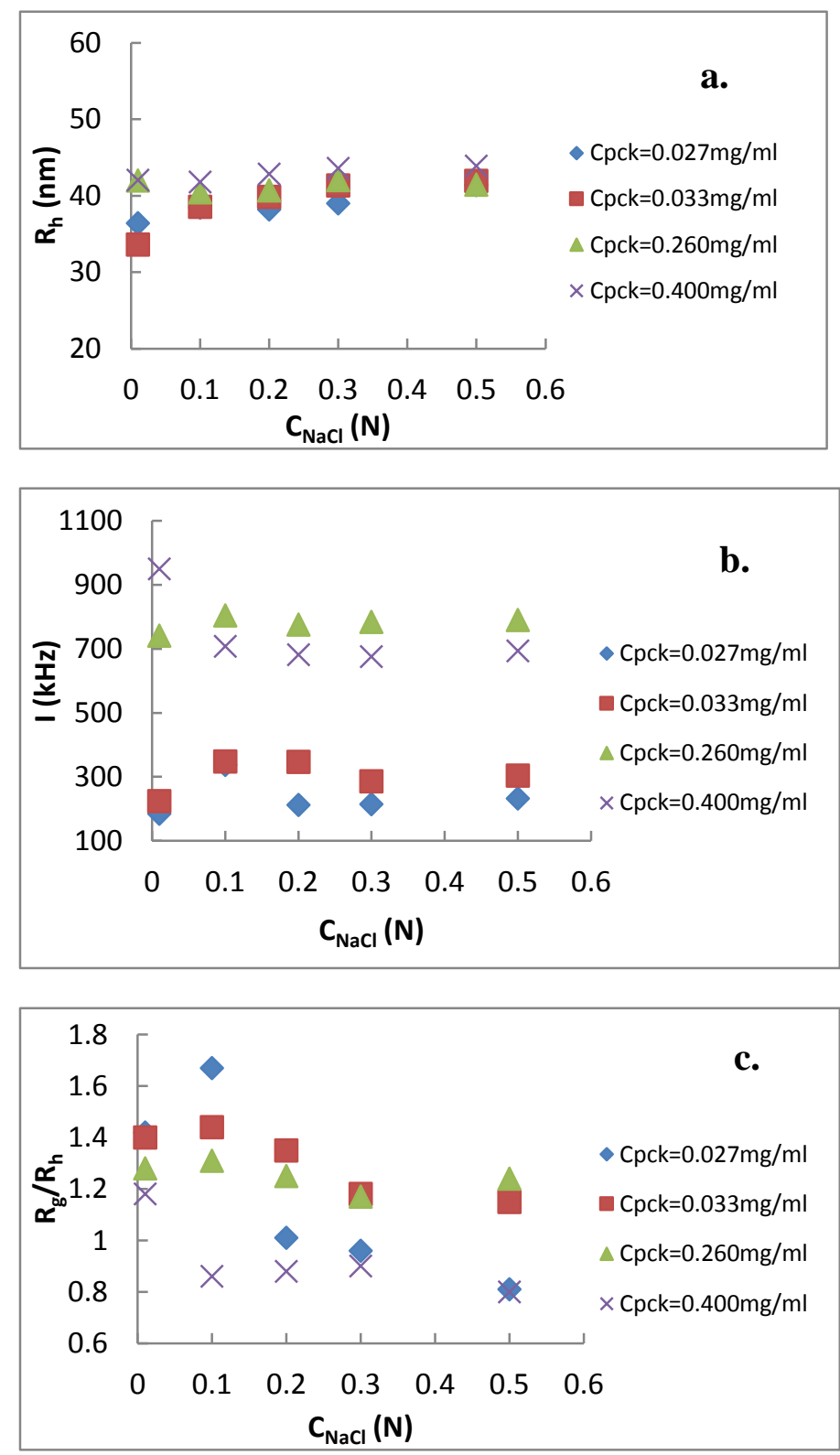

Fig. 4. (a) Hydrodynamic Radius, $\mathrm{R}_{\mathrm{h}}$, (b) light scattering intensity at $90^{\circ}, \mathrm{I}$, and (c) $\mathrm{R}_{\mathrm{g}} / \mathrm{R}_{\mathrm{h}}$, as a function of the added $\mathrm{NaCl}$ concentration of representative solutions, corresponding to low and high $\mathrm{C}_{\mathrm{PCK} 3145}$, of the QNPHOSEO:PCK3145 system at $\mathrm{pH}=7.00$. 

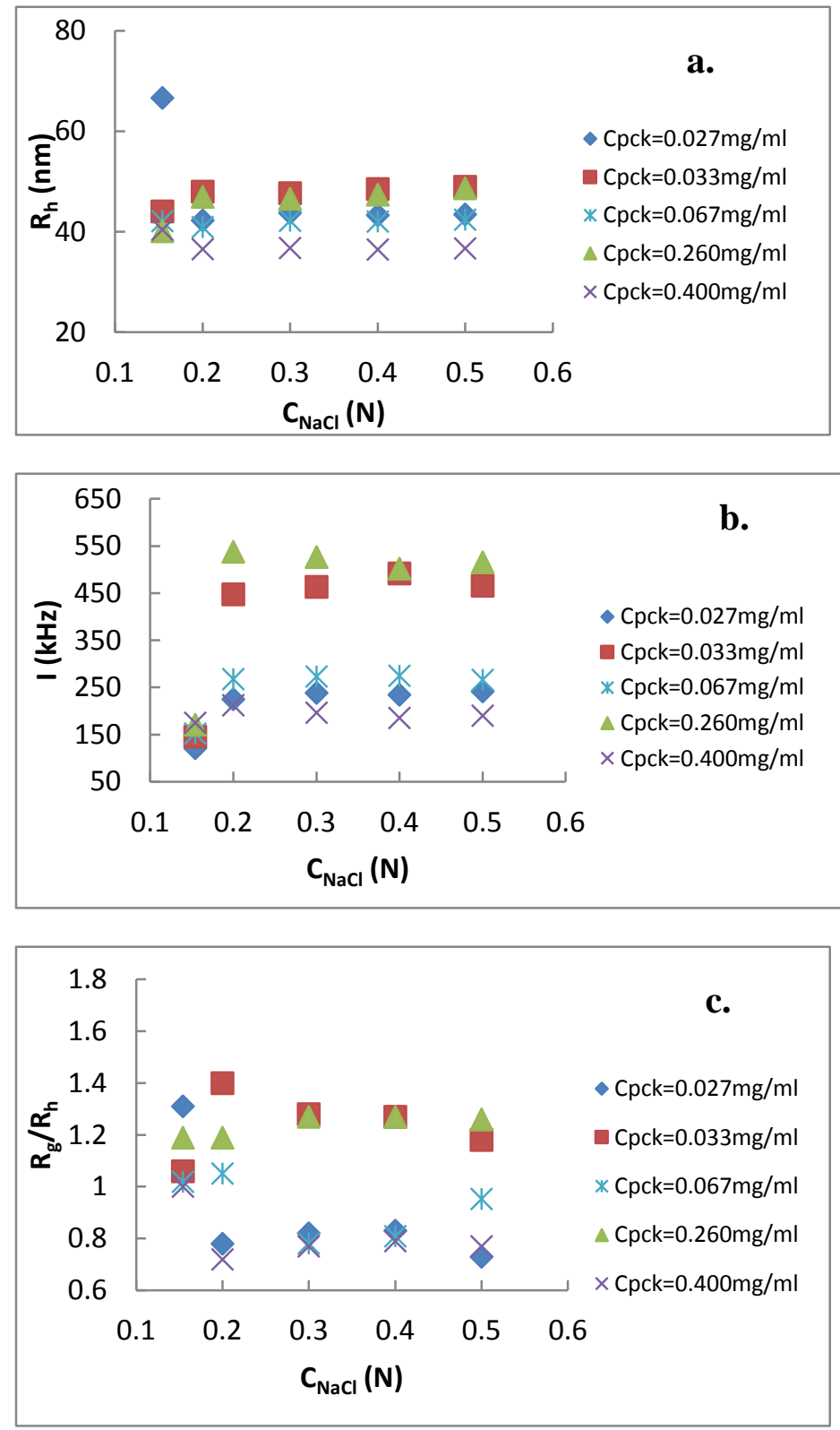

Fig. 5. (a) Hydrodynamic Radius, $\mathrm{R}_{\mathrm{h}}$, (b) light scattering intensity at $90^{\circ}, \mathrm{I}$, and (c) $\mathrm{R}_{\mathrm{g}} / \mathrm{R}_{\mathrm{h}}$ as a function of the added $\mathrm{NaCl}$ concentration of representative solutions, corresponding to low and high $\mathrm{C}_{\mathrm{PCK} 3145}$, of the QNPHOSEO:PCK3145 system at $\mathrm{pH}=7.40$. 


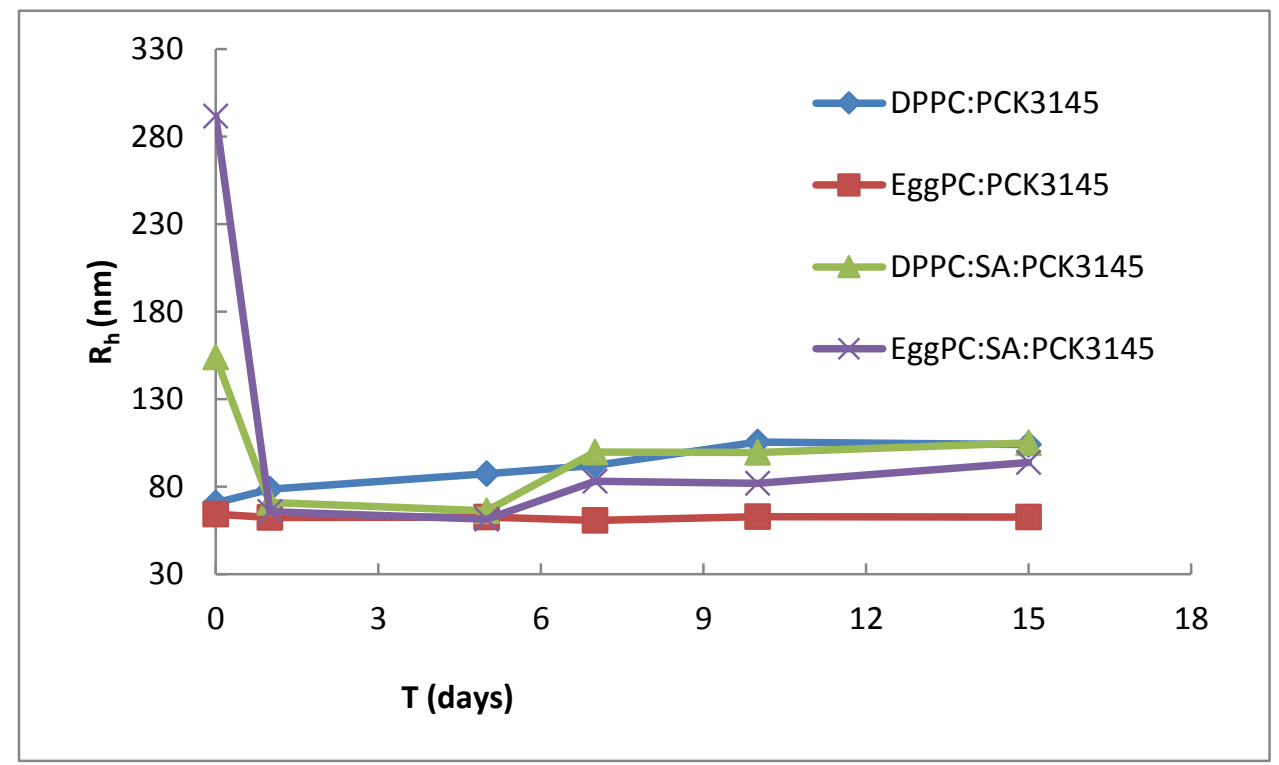

Fig. 6. Stability assessment of the liposomal nanoparticles: DPPC:PCK3145 (9:0.2 molar ratio), EggPC:PCK (9:0.2 molar ratio), DPPC:SA:PCK3145 (9:1:0.2 molar ratio) and EggPC:SA:PCK3145 (9:1:0.2 molar ratio). 


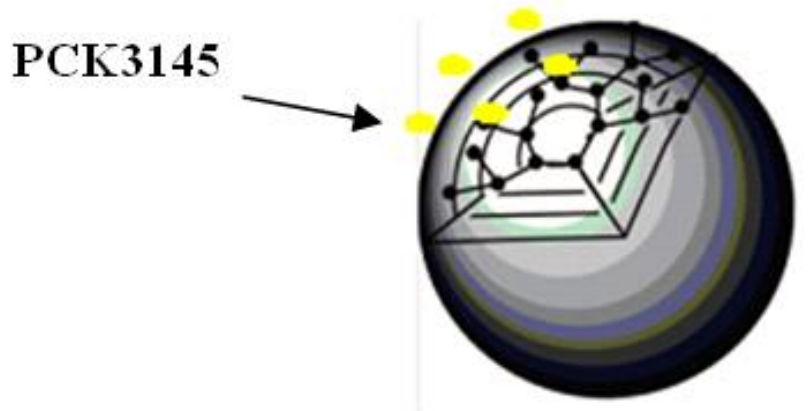

Scheme 1: The structure of dendritic nanoparticles complexing tigapotide. 


\section{Caption List}

Fig. 1. Molecular structure of a. tigapotide (PCK 3145), b. QNPHOSEO-9 polyelectrolyte block copolymer (the degrees of polymerization are $\mathrm{m}=162$ and $\mathrm{n}=334$ ) and c. PAMAM G-4 dendrimer.

Fig. 2. (a) Hydrodynamic Radius, $\mathrm{R}_{\mathrm{h}}$, (b) Polydispersity Index, (PD.I.), (c) $\zeta$ potential, (d) light scattering intensity at $90^{\circ}$, I, and (e) $\mathrm{Rg} / \mathrm{R}_{\mathrm{h}}$ as a function of $\mathrm{C}_{\mathrm{PCK} 3145}$, for the solutions of QNPHOSEO:PCK3145 system at $\mathrm{pH}=7.00$ and $0.01 \mathrm{M}$ $\mathrm{NaCl}$ (blue points) and at $\mathrm{pH}=7.40$ and $0.154 \mathrm{M} \mathrm{NaCl}$ (red points).

Fig. 3. (a) Hydrodynamic Radius, $\mathrm{R}_{\mathrm{h}}$ and (b) $\zeta$-potential, as a function of $\mathrm{C}_{\mathrm{PCK} 3145}$, for the solutions of QNPHOSEO:PCK3145 system at $\mathrm{pH}=7.00$ and $0.01 \mathrm{M} \mathrm{NaCl}$ (blue points) and at $\mathrm{pH}=7.40$ and $0.154 \mathrm{M} \mathrm{NaCl}$ (red points) at $\mathrm{FBS}$.

Fig. 4. (a) Hydrodynamic Radius, $\mathrm{R}_{\mathrm{h}}$, (b) light scattering intensity at $90^{\circ}, \mathrm{I}$, and (c) $\mathrm{R}_{\mathrm{g}} / \mathrm{R}_{\mathrm{h}}$, as a function of the added $\mathrm{NaCl}$ concentration of representative solutions, corresponding to low and high $\mathrm{C}_{\mathrm{PCK} 3145}$, of the QNPHOSEO:PCK3145 system at $\mathrm{pH}=7.00$.

Fig. 5. (a) Hydrodynamic Radius, $R_{h}$, (b) light scattering intensity at $90^{\circ}, I$, and (c) $\mathrm{R}_{\mathrm{g}} / \mathrm{R}_{\mathrm{h}}$ as a function of the added $\mathrm{NaCl}$ concentration of representative solutions, corresponding to low and high $\mathrm{C}_{\mathrm{PCK} 3145}$, of the QNPHOSEO:PCK3145 system at $\mathrm{pH}=7.40$.

Fig. 6. Stability assessment of the liposomal nanoparticles: DPPC:PCK3145 (9:0.2 molar ratio), EggPC:PCK (9:0.2 molar ratio), DPPC:SA:PCK3145 (9:1:0.2 molar ratio) and EggPC:SA:PCK3145 (9:1:0.2 molar ratio).

Scheme 1. The structure of dendritic nanoparticles incorporating tigapotide. 